\title{
Possible usage of foreign practice of mortgage lending in Russia
}

\author{
Denis Ushakov ${ }^{1, *}$, Diana Stepanova ${ }^{2}$, and Mariia Ermilova ${ }^{2}$ \\ ${ }^{1}$ IC, Suan Sunandha Rajabhat University, 1 U-Thong Nok rd, 10200 Dusit, Bangkok, Thailand \\ ${ }^{2}$ Plekhanov Russian University of Economics, 117997, Stremianny lane 36, 115093, Moscow, Russia
}

\begin{abstract}
The article compares the mechanisms of mortgage lending in Russia and abroad, examines how the methods of German mortgage lending can be applied in Russian practice. The possibility of using the German credit product "Bausparsumme" in Russia and its impact on the riskiness and profit of Russian banks are investigated. the aim of this work is to compare mortgage lending in Russia and abroad and to examine how the methods of the German mortage lending can be transferred to Russian, in particular its vital to investigate the impact of such product on the riskiness and profit of Russian banks.
\end{abstract}

\section{Introduction}

Mortgage lending exists in Russian Federation for almost 20 years since first laws enabling it were introduced. During that period the market, financial and macroeconomic conditions experienced many changes. The world and the Russian federation in particular have both seen and experienced the consequences of the world economic crisis of 2007-2008; the recent sanctions imposed on the country have played an important role in its development as well, so did the changes in the oil prices some years ago. As a result, many important economic indicators changed which affected the ability of citizens to pay out their debts, including mortgage payments.

Moreover, some lost the ability to afford a mortage and therefore are in a high need for dwelling. In order to stimulate demand, banks decided to decrease interest rates on mortgages and the Central Bank started thinking of lowering the reserve requirements. Although such measures can increase the demand for mortgage and therefore provide more families with a place to live, in the long- term perspective it seems to be a risky initiative, as ,in case of default, the collateral should be sold in order for the bank to restore its position, but it may be difficult to find a buyer as overall wealth of the citizens is not that high to buy a house with own funds, therefore the sale leads to a new mortgage loan; if many default on their loans as a result of high inflation or increased unemployment many banks can simply disappear and go bankrupt; or simply there will be no customers as many still cannot afford a mortgage even at current interest rates. The share of mortgage in Russia's GDP is one of the lowest among European countries.

${ }^{*}$ Corresponding author: denis.us@ssru.ac.th 
Therefore, in order to increase profitability of mortgage products and lower risks, Russian commercial banks should include specific mortgage lending products into their portfolio which are popular in countries using European banking model.

The mortgage products originating from the European banking model exist for centuries and are to some extent less complex than those used in the American model, which normally require the issue of the Mortage-backed-security. For example, in Germany many families have purchased property with the help of mortgage savings contracts and such contracts are still popular in the country even though there is a variety of products that banks currently offer to customers [1]. The main feature of such products are lower risk and interest rates, although being attractive for banks from the point of view of a margin, that is why they can have a positive impact on Russian banks' profits and risk positions, as well as remain beneficial for society at the same time.

Topicality of the chosen subject is dictated by the current conditions of mortgage loans as well as by the economic situation in the country. The interest rates of $8-9 \%$ are very high for many customers especially during tough economic position, with inflation and exchange rates rising [2]. The implementation of the new mortgage product basing on the European experiences can offer lower interest rates to the customers therefore increasing the demand for the mortgage products, which, in effect, should have a positive influence on the profits of Russian commercial banks.

\section{Methods}

There are two different mortgage models known currently. The first one is the American model. Making a rough and simple description, the main principle of such system is that bank lends a sum of money to a borrower and takes the property as a collateral. Afterwards it can sell the loan to the government agency, which later on pools several mortgages and sells bonds on these pools to investors. Therefore, market players maintain the liquidity. Such model operates in the US, England and Australia. The prerequisite for such system was so called Savings\& Loan crisis in 1980- 1990, when the lack of capital forced mortgage lending institutions to move such loans from the balance sheet by the means of securitization [3].

The other model is the European mortgage model, where mortgage banks are the main players [4]. This model is widely used in such countries as Germany or France and was known and used in Russia prior to the revolution. The main difference is that loans are not sold off from the balance sheet and remain there. Using the example of Germany, it could be shown how such systems operates [4-6].

There is special class of institutions called "Bausparkasse" (Mortgage- savings bank), where a person who wants to obtain mortgage financing initially makes a contract with the bank, in accordance to which he must invest a certain sum of money into the bank and should increase this sum up to a certain amount during negotiated period of time. After that period, the bank has an obligation to grant a loan to the borrower. The main peculiarity here is that both savings part of the contract and loan part of the contract bear lower interest rate than that on the market [7].

Currently, it could be concluded that more elements of American system are implemented in Russia. The current widespread mortgage scheme in Russia will lead to a concentration of mortgage market risks at the federal level, as a single-tranche securitization system and a monopoly scheme to stimulate the growth of the mortgage market are developing. The Russian Ministry of Finance, however, declares a conscious choice of the current model as taking into account the negative experience of the USA. Butwe see this as a key risk of nationalization of mortgages. 
The "Savings system" is widely used in Germany to finance acquisition of property rights and the main player in this system is a mortgage savings bank. Being described in a simple manner, financing takes place via named institutions, which cumulate financial resources for the perspective loans by using sources as following: deposits of customers at mortgage savings banks, payments of borrowers made on usage of housing loan, as well as the state premium, which is paid in accordance with the savings contract given that the deposit or invested a certain amount into his account during the year. In this case, housing loans are only available to the depositor of a mortgage savings bank after a certain time period which lasts from 5 to 6 years on average.

During this time a person makes monthly contributions in the amount defined in the contract. Interest rates on deposits and loans are fixed for the whole period of the duration of the contract. Repayment on the housing loan is made within the time frame specified in the contract with the maximum loan repayment period of 12 years. Interest rates usually lie below market rates.

The next phase is the loan phase, when the depositor repays the credit which is divided into equal amounts with respect to the savings amounts within a period of 10-15 years under fixed interest rate (Darlehenszinssatz) which is on average $4-4.5 \%$ annually and during which the payments are made according to the predefined schedule of payments. The volume of loan is the difference between cumulated funds during savings phase and amount stated in the contract at the beginning [8].

As it was mentioned above, the interest rate is lower than the market one, it is linked to the deposit rate of the savings contract and exceeds it by a fixed rate ( $2 \%$ on average) and the fixed interest rate is applied for the whole period oftime.

It should be mentioned that in Germany the amount of the mortgage savings contractamountsto50-60\%oftheproperty'svalue.Therestisfinancedbyownfunds or by a mortgage loan, this is why the combination of loans written by mortgage savingsbanksandloansgrantedbymortgagebanksiswidelyused,ashavingacontract with mortgage savings bank allows the borrower to obtain funding in mortgage banks with no proof of creditworthiness.

\section{Results}

The essential part of implementation of any bank product is the estimation of its risk, as latest trends in banking. The significance of risk calculation increased especially after the recent banking crisis, when Basel recommendations tightened,and banks started following the recommended procedures in order to remain stable and ensure sectors overall stability, as well as to minimize the consequences of future financial crisis.

For the purpose of risk estimations, the Monte-Carlo simulation will be used in combination with scenario analysis. In order to maintain simplicity and facilitate the understanding of the concept, only one contract will be analyzed therefore the case when only one person is involved.

First of all, we should refer to the Central Bank statics on HML debt to find out the volume of overdue payments and calculate the default rates on mortgage (table 1).

Now we can run the simulation with above mentioned inputs. As a result, weobtain the Figure 1. The blue bars represent the assumption values or values that were generated by the Monte-Carlo simulation, the green background represents the shape of the normal distribution. There are several parameters such as the Confidence level of $95 \%$, which we received after the simulation of 10000 trials. 
Table 1. HML 90+ days payments overdue.

\begin{tabular}{|c|c|c|}
\hline & Absolute (mln.RUB) & $\%$ \\
\hline 2011 & 71,042 & $6.94 \%$ \\
\hline 2012 & 70,586 & $6.25 \%$ \\
\hline 2013 & 60,047 & $4.06 \%$ \\
\hline 2014 & 50,330 & $2.52 \%$ \\
\hline 2015 & 54,037 & $2.04 \%$ \\
\hline 2016 & 75,154 & $2.13 \%$ \\
\hline 2017 & 120,662 & $3.03 \%$ \\
\hline 2018 & 119,069 & $2.65 \%$ \\
\hline 2019 & 113,606 & $2.19 \%$ \\
\hline
\end{tabular}

The construction of the boundaries for confidence levels enables us to calculate the Value at Risk. First of all, we should check whether all our trials fall within the given intervals from $0.41 \%$ to $6.54 \%$ and make some adjustments so that the simulation could become statistically valid. After having excluded values which do not fall within the interval, only 8999 are left for the VAR calculations.

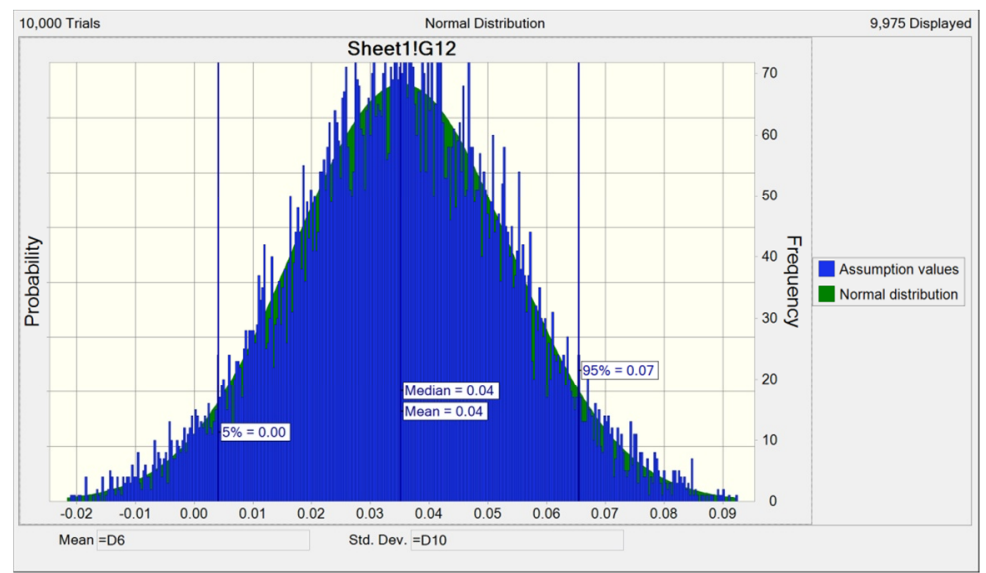

Fig. 1. Normal distribution of default rates.

Secondly, we should now obtain values of the average property values for the Russian Federation in order to define the monetary value that banks usually lend to the households in the form of the mortgage loan and then to apply it to the mortgage savings contract.

The statistics of Bank of Russia on mortgage loans provides us with the average volume of the loan per contract which was 1,719,065.37 RUB in 2017 and which should be equal to the average price of the property such as a flat or a house, as bank do not usually lend more that the house actually costs, as it is used as a collateral.

The third step in the VAR calculations is to multiply the default rates by $1 / 2$ of the of the property value in order to construct the frequency distribution for the VAR based on 8999 default values. Here it also should be explained why only $1 / 2$ of the property value should be taken therefore we should refer to the basics of the contract. 
Table 2. A brief summary of the Monte- Carlo simulation, 10000 runs.

\begin{tabular}{|c|c|c|c|c|c|}
\hline Trial values & G12 & Lower & Upper & Output & Default value (rub.) \\
\hline 1 & $3.34 \%$ & $3.34 \%$ & $3.34 \%$ & $3.34 \%$ & $28,684.68$ \\
\hline 2 & $2.19 \%$ & $2.19 \%$ & $2.19 \%$ & $2.19 \%$ & $18,821.96$ \\
\hline 3 & $0.42 \%$ & $0.42 \%$ & $0.42 \%$ & $0.42 \%$ & $3,598.18$ \\
\hline 4 & $5.28 \%$ & $5.28 \%$ & $5.28 \%$ & $5.28 \%$ & $45,343.24$ \\
\hline 5 & $3.74 \%$ & $3.74 \%$ & $3.74 \%$ & $3.74 \%$ & $32,113.75$ \\
\hline 6 & $0.24 \%$ & not in $5 \%$ & not in $95 \%$ & & - \\
\hline 9995 & $9.93 \%$ & $9.93 \%$ & not in $95 \%$ & & - \\
\hline 9996 & $2.35 \%$ & $2.35 \%$ & $2.35 \%$ & $2.35 \%$ & $20,225.39$ \\
\hline 9997 & $5.51 \%$ & $5.51 \%$ & $5.51 \%$ & $5.51 \%$ & $47,343.55$ \\
\hline 9998 & $1.16 \%$ & $1.16 \%$ & $1.16 \%$ & $1.16 \%$ & $9,930.84$ \\
\hline 9999 & $1.01 \%$ & $1.01 \%$ & $1.01 \%$ & $1.01 \%$ & $8,716.39$ \\
\hline 10000 & $3.04 \%$ & $3.04 \%$ & $3.04 \%$ & $3.04 \%$ & $26,115.32$ \\
\hline
\end{tabular}

Now we are ready to analyze outputs or default values which are presented in the Table 3. For this purpose, we have to construct the frequency distribution of the values. Firstly, we should use "MIN" and "MAX" functions to define the lowest and the highest value among those that we have calculated and therefore to construct the lowest and the highest boundary.

We use EXCEL function we create the frequency as shown in the Figure 2 for the determined bins and divide them by 8999 or count of simulations within the intervals to get the obtain the relative values for the Y-axis of the graph.

\section{Value at Risk}

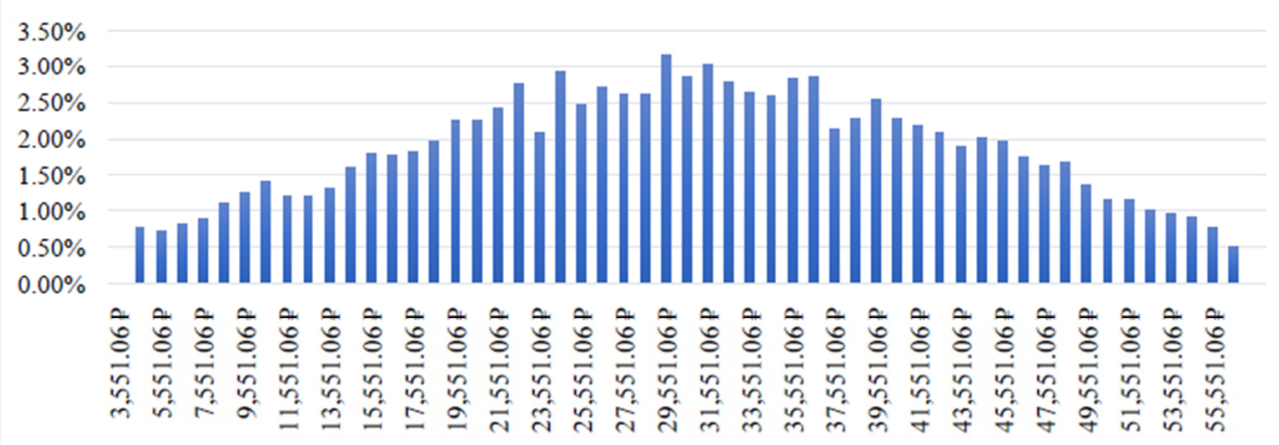

Fig. 2.Value at Risk frequency distribution.

Now we are able to conclude that with the $95 \%$ Confidence Level the bank will not lose more than 56,214.28 RUB in the worst case given the normal scenario which is exactly $6.54 \%$ or the highest boundary. The most frequent case, however, is the VAR value of $29,551.06$ RUB or the default rate of $3.44 \%$.

Although the relative measures of both products may remain the same, the absolute measures of VAR of the mortgage savings loan are twice lower than the usual mortgage loan and, in addition to that, in the worst case the loss from the mortgage savings contract 
on average is lower by $2,887.85$ RUB than in the most frequent case of the usual mortgage product.

Besides, the impact of a mortgage savings contract on the overall mortgage lending market will reduce the possible default rates, even though it is hard to quantify the impact currently as no historical experience exists therefore the measures cannot beobtained.

Now when we defined the required economic indicators we can start creating the linear regression. Unfortunately, Bank of Russia has the statistics on default rates since 2010 only, as a result we can hardly construct a proper linear regression on annual basis, as we would have had 7 points only. However, we can create a regression based on data which is provided monthly.

The first thing to do, before constructing a multiple linear regression with the help of EXCEL is to put the data together and then define extreme outliers which may affect the predictive power of the linear regression. In this particular case, we will define the extreme outliers as indicators that differ by more than $30 \%$ from the same of the previous period. For instance, the real average monthly wage should change quite smoothly from one month to another, however, we evidenced in the gathered data that in some months there was an increase in the real average monthly wage of more than $30 \%$ in one month and then a decrease by approximately $27 \%$ in the subsequent period, therefore we can assume such points of increase represent the extreme outliers.

After having eliminated the extreme outliersweshould now create the correlation matrix with the help of the EXCEL's Data Analysis tool pack [9]. This is a very important step in the process of creation of the multiple regression analysis as it enables us to define the correlation between independent variables. The Table 3 demonstrates the output of the correlation matrix.

Table 3. Correlation matrix.

\begin{tabular}{|c|c|c|c|}
\hline & Default rate & Unemployment & AV wage \\
\hline Default rate & 1 & & \\
\hline Unemployment & 0.871760642 & 1 & \\
\hline AV wage & -0.754482294 & -0.739010561 & 1 \\
\hline
\end{tabular}

Having analyzed the correlation coefficients between two variables, we can conclude that both are not highly correlated with each other and the error of multicollinearity is eliminated, therefore we should not exclude one of them from the regression model. When all the preliminary steps are completed we move to the next task and run the linear regression.

Table 4. Regression statistics on collected data.

\begin{tabular}{|c|c|}
\hline Multiple R & 0.980585374 \\
\hline R Square & 0.961547676 \\
\hline Adjusted R Square & 0.949472649 \\
\hline Standard Error & 0.007679417 \\
\hline Observations & 88 \\
\hline
\end{tabular}


Table 5. Analysis of Variance.

\begin{tabular}{|c|c|c|c|c|c|}
\hline ANOVA & & & & & \\
\hline & $d f$ & $S S$ & $M S$ & $F$ & Significance $F$ \\
\hline Regression & 2 & 0.126824494 & 0.063412247 & 1075.267906 & $4.48317 \mathrm{E}-61$ \\
\hline Residual & 86 & 0.005071716 & $5.89734 \mathrm{E}-05$ & & \\
\hline Total & 88 & 0.13189621 & & & \\
\hline
\end{tabular}

Table 6. Base-case scenario of default rates.

\begin{tabular}{|c|c|c|}
\hline & 2020 & 2021 \\
\hline Unemployment rate & $5.5 \%$ & $5.3 \%$ \\
\hline Real average monthly wage & 39649.98312 & 39808.58305 \\
\hline Default rate & $1.92 \%$ & $1.68 \%$ \\
\hline
\end{tabular}

As we can see, although the real average monthly wage increased by $0.4 \%$ in 2021 only, the decrease in unemployment rate influenced the default rates dramatically and reduced it to $1.68 \%$ with the lowest predicted defaults in the history. Although the base case scenario provides us with positive development of default rates based on the equation of linear regression, it is still not the only scenario to be considered. Moreover, there could exist additional factors which are not included in the model there for the results may be affected by them [10]. The main stress of the base case should be imposed on the Monte- Carlo simulation as the methods tend to be more accurate and more reliable one. Despite that, we need the base-case scenario to proceed to the best-case scenario and the worst-casescenario.

To create the worst-case scenario, we will insert the lower year over year growth of the real wage and higher unemployment rate than it was used for the computations of the basecase scenario.

Table 7. Worst-case scenario of default rates.

\begin{tabular}{|c|c|c|}
\hline & 2020 & 2021 \\
\hline Unemployment rate & $5.70 \%$ & $5.60 \%$ \\
\hline Real average monthly wage & 38894.74535 & 39050.32433 \\
\hline Default rate & $2.22 \%$ & $2.09 \%$ \\
\hline
\end{tabular}

As it is shown in the Table 7, in the worst-case scenario we assume that the unemployment rate will be $0.2 \%$ and $0.3 \%$ higher than in the base-case scenario in years 2020 and 2021 respectively; the real average monthly wage under the assumptions will grow $3 \%$ only versus $5 \%$ as stated in the economic forecast, the growth of $0.4 \%$ in the 2021 remained unchanged.

Despite all negative assumptions, the trend of lowering default rate remains in the scenario, however it is hard to predict the development of the indicator for the period larger than1-year time, therefore we will not use the forecasted figures for 2021 as ones which we can use to make decisions and they will be used for illustrative purposes only.

Thelastscenariotobegeneratedisthebest-casescenario.Althoughweshould increase the average wage and decrease unemployment rate, no drastic changes are going to be introduced as scenario analysis should remain unbiased and it is not the most important scenario compared to the base-case and worst-case scenarios. The Table 8 represents the default rates calculated for the best-case scenario. In the best-case scenario, we assume that unemployment will be $0.1 \%$ and $0.05 \%$ lower than in the base case scenario in 2020 and 
2021 respectively. Moreover, we assume a growth in real wages of 5.5\% for 2020 instead of $5 \%$ although the growth of $0.4 \%$ for 2021 remains the same as in the base casescenario.

Table 8. Best-case scenario of default rates.

\begin{tabular}{|c|c|c|}
\hline & 2020 & 2021 \\
\hline Unemployment rate & $5.40 \%$ & $5.25 \%$ \\
\hline Real average monthly wage & 39838.79256 & 39998.1477331919 \\
\hline Default rate & $1.79 \%$ & $1.61 \%$ \\
\hline
\end{tabular}

Overall, the scenario analysis remains a good tool for the simulation of the future risks, however it should be used in combination with the Monte-Carlo simulation as it gives more information about possible outcomes with given probabilities, while scenario analysis offers only three possible cases, the probabilities of which are not given in the estimations. Consequently, the combination of both methods can be seen as a reliable estimate and therefore could be used to make clear and correct conclusions. Using both methods we have determined the potential default rates for the product using the scenario analysis and, more importantly, we determined the maximum amount of value at risk with the help of the Monte-Carlo simulation that Russian banks may be exposed to lose in the extreme case, that is if defaults increase.

The maximum value at risk of this mortgage product equals to 56,214.28 RUB in the case when default rate is equal to $6.54 \%$. Given that we have concluded that even in the worst case the mortgage savings contract is still more attractive for the bank from the risk point of view, as the loss would be 2 times lower than the loss in the normal case that refers to the usual mortgage loan, not mentioning that such product can lower default.

The next financial results are presented in the Table 9 and reflect the loan phase of the mortgage savings contract. The first row to analyze is the annual interest rate on the loan, based on the analysis of the savings phase above, we state that it can be $7.25 \%$ annually. The next assumption that we make is that a customer makes a monthly loan payment including interest which is equal to $11,825.85 \mathrm{RUB}$ within 8 -year period at monthly rate of $0.60417 \%$.

Table 9. Loan phase of mortgage savings contracts.

\begin{tabular}{|c|c|}
\hline Annual interest rate (a) [rate] & $7.25 \%$ \\
\hline Payment periods per year (b) & 12 months \\
\hline Number of years (c) & 8 \\
\hline Periodic rate (a) / (b) & $0.60417 \%$ \\
\hline Total number of periods (b) * (c) [nper] & 96 \\
\hline Periodic payment [pv] & $11,825.85$ RUB \\
\hline Loan value & $859,532.69$ RUB \\
\hline
\end{tabular}

The last step to be calculated is the net interest income before provision for credit losses, as those are hard to be measured with no information such ratio, as no particular bank is taken for the calculations, therefore the figure could be calculated by each credit institution using their own rates and conditions. For the purpose of calculation, we subtract the revenue from the defined costs of the mortgage savings contract and receive the net interest income before provision for credit losses in the amount of 129,319.46 RUB. 


\section{Discussions}

Based on the scientific results obtained in this paper several conclusions could be drawn as follows:

1. The mortgage savings contract can significantly lower risks of Russian commercialbanks.

The obtained results have proven that mortgage savings contract are two times less risky compared to the normal mortgage loans that are currently the only available source of HML in the Russian Federation.

One of the main risk benefits associated with the product is that the loan is generally two times lower amount compared to the normal loan; therefore the value at risk of a bank is $50 \%$ smaller as well [11]. Additionally, even at extreme high default rates of more than $6 \%$ the loss associated with the product is still smaller than an average loss at most frequent default rates of nearly $3 \%$. That is especially important to consider if we look at the responsiveness of default rates to changes in the unemployment rates and average wage fluctuations, as even small increase in unemployment in combination with slow growth of real average monthly wages can lead to dramatic increase of default rates, as it was presented by linear regression in the scenario analysis.

Another positive impact of the mortgage savings contracts, which shall reduce the risks of commercial banks cannot be quantified. However, it should be explicitly described as this is a qualitative impact of the product on the overall ability of the citizen store pay their debts. The product should reduce the default rates, as the amount that it to be repaid under it is two times lower than one that is usually to be repaid under normal mortgage loans given same or even greater maturity, as both interest ratesand principle are significantly lower if we speak about mortgage savings contract. In addition to that, the participants of mortgage savings contracts prove their credit standing by depositing quite similar amounts monthly during the savings phase, so mostly creditworthy customers will be eligible for the loan, not to mention that such conditions make even more citizens eligible for the loan and therefore creditworthy. As a result, less loans will be doubtful and mortgage default rates will decrease soon.

Mortgage savings contracts should help the banks to maintain the long- term health and stability as they increase asset quality of the financial institution [12]. Given the recent trends in increased mortgage lending combined with high level of defaults on commercial credits and low development of real estate market, which reduces the property value if bank has to sell a collateral in case of default, we may expect a decrease in asset quality of the banks. The reason for that would be that new borrowers may struggle to pay out their debts at $8.5 \%$ interest within 30 years assuming the price of the property, if they have difficulties with repaying consumer credits which are 100000 RUB on average. However, the mortgage savings contracts are shorter in term and more beneficial in terms of interest, therefore it would be hard to default onit.

2. The mortgage savings contract can facilitate the increase of profits of Russian commercial banks.

Even though, it was not proved that the mortgage savings contracts occur to be more profitable for a bank than mortgage loans due to the absence of information on interest expenses of the bank, net interest income for the mortgage savings contract before provision for credit losses was recorded as a result of author's calculations based on the assumptions provided. That means that banks can earn profits if they include such products in their portfolios, given that they find proper combinations for both savings and loan phase conditions.

Additionally, despite the fact that such products are proven to increase profits by being more lucrative for the banks than mortgage loans, they still have an opportunity to boost 
profits by allowing more people to take mortgages as offered conditions are by far more attractive than those offered by many mortgage loans in Russia, both in terms of smaller duration of 15 years, on average, and in term of interest rates being much lower than those offered on the market. Therefore, the profits can be increased as more customers will be attracted by the product.

Mortgage savings contracts can additionally maintain the long-term financial stability of Russian banks, as current trends in Russia of low interest rates on mortgage and relatively high interest rate on deposits, reduce bank's margin, as a result the profits may shrink in the long run which can have negative consequence in case of financial instability and decrease in revenues from other interest and non- interest-bearing products.

\section{Reference}

1. N. Hang Chan, Handbook of Financial Risk Management: Simulations and Case Studies. (Wiley Handbooks in Financial Engineering and Econometrics, 2013).

2. M. Crouhy, D. Galai, R. Mark, The Essentials of Risk Management. (McGraw-Hill, 2014).

3. P. Jorion, Financial Risk Manager Handbook (McGraw-Hill, 2014).

4. T. J. Pinkowish, Residential Mortgage Lending: Principles and Practices (Cengage Learning, 2013).

5. S. Heffernan, Modern Banking (Wiley Finance, 2006).

6. A. Saunders, M. M. Cornett, Financial Institutions Management: A Risk Management Approach (2018).

7. R. Fischer, Bausparen 2017: Zahlen, Daten, Fakten (Haufe, 2017).

8. H. Burghof, S. Kirmße, Bausparenheute - Herausforderungen und Perspektiven (ZEB, 2018).

9. Y. Holynskyy, I. Onyusheva, EUrASEANs 1(14), 16 (2019).

10. S. Bouyon, Recent Trends and Developments in European Mortgage Market (McGrawHill, 2014).

11.M. Schneider, Housing Markets in Austria, Germany and Switzerland https://www.oenb.at/dam/.../mop_2015_q1_analyses4.pdf

12. J. Breeden. Monte Carlo scenario generation for retail loan portfolios. https://www.researchgate.net/publication/220636352 